BMJ Open Sport \& Exercise Medicine

\title{
Physical inactivity: productivity losses and healthcare costs 2002 and 2016 in Sweden
}

\author{
Kristian Bolin ${ }^{1,2}$
}

To cite: Bolin K. Physical inactivity: productivity losses and healthcare costs 2002 and 2016 in Sweden. BMJ Open Sport \& Exercise Medicine 2018;4:e000451. doi:10.1136/ bmjsem-2018-000451

Accepted 18 September 2018

Check for updates

(C) Author(s) (or their employer(s)) 2018. Re-use permitted under CC BY-NC. No commercial re-use. See rights and permissions. Published by BMJ.

${ }^{1}$ Department of Economics, University of Gothenburg, Gothenburg, Sweden

${ }^{2}$ Centre for Health Economics, University of Gothenburg, Gothenburg, Sweden

Correspondence to Dr Kristian Bolin; kristian.bolin@ economics.gu.se

\section{ABSTRACT}

Objectives To estimate the costs associated with physical inactivity in Sweden for the year 2016. Methods The costs associated with insufficient physical activity was calculated employing population attributable fractions (PAFs) and register information on healthcare utilisation, mortality and disability pensions. The PAFs were calculated using information on exercise habits and morbidity-specific relative risks. The healthcare cost components were calculated based on registry data on inpatient-care, outpatient-care and primary care utilisation. Registry data on cause-specific mortality and granted disability pensions were used to calculate the productivity loss components. Costs associated with pharmaceutical utilisation were not included due lack of data.

Results Physical exercise habits improved somewhat between 2002 and 2016. Thus, the associated morbidityspecific PAFs decreased over the same time period. Conclusions The economic costs attributable to insufficient physical activity decrease between the year 2002 and 2016. Healthcare costs attributable to insufficient physical activity as share of total healthcare expenses increased from $0.86 \%$ in 2002 to $0.91 \%$ in 2016.

\section{INTRODUCTION}

There is ample empirical evidence that physical activity improves (current) well-being and reduces future risks of disease. Thus, physical activity presently exerted has both an immediate welfare enhancing effect as well as a precautionary investment effect. While the immediate effect on welfare is strictly private, the reduction in risks of disease influences both private and public domains. It has been shown that physical activity improves health and promotes longevity. ${ }^{1-4}$ Physical activity reduces the risk of (1) cardiovascular disease ${ }^{56}(2)$ hypertension and stroke ${ }^{7-9}(3)$ type 2 diabetes, ${ }^{10-16}$ (4) colon cancer, ${ }^{17-20}$ (5) breast cancer, $^{21-23}$ (6) osteoporosis ${ }^{24-26}$ and (7) depression and anxiety. ${ }^{27-30}$

In spite of the large and well established health effects and general well-being effects of physical activity, a significant proportions of adult population do not exert any physical activity at all or are irregularly physically active (we will refer to this as being insufficiently physically activity). The WHO reports that $25 \%$ of the adult global population is insufficiently physically active. The proportion of the adult Swedish population that partake in physical activity regularly has risen over the last three decades, from about $30 \%$ in the early 1980 s to more than $60 \%$ in the early 2010s. The proportion of women who are regularly physically active was somewhat below that of men in the early 1980s. Since then, the proportion of active women has risen more than that of men, and in the early 2010s, the proportion exceeded that of men (Survey of Living Conditions, Statistics Sweden).

The economic burden imposed on societies of physical inactivity, or insufficient physical activity, is considerable. The costs that arise due to the adverse health effects of physical inactivity have been estimated in a small number of studies. ${ }^{31-41}$ The literature on the economic burden of physical inactivity was summarised in a recent systematic review. ${ }^{42}$ Studies published in the peer-reviewed international literature have been performed for, inter alia, Australia, Canada, China, Japan, New Zeeland, the UK, the USA and Switzerland. In addition, Ding et al calculated the global economic burden of physical inactivity, divided per country, employing the prevalence approach and extrapolated healthcare unit costs. ${ }^{42}$ Estimated proportions of national healthcare expenditures attributable to inadequate physical activity were estimated in the range $0.3 \%-4.6 \%$. Estimated productivity losses varied between studies due to different methodologies. ${ }^{42}$ To date, no study of the costs of inadequate physical activity among Swedish adults employing Swedish data has been published. This study fills in that gap by presenting such cost estimates for Sweden for the years 2002 and 2016.

\section{Material and methods}

The opportunity cost of illness is conceptually comprised of direct and indirect costs. Direct 
and indirect costs are the values of the resources used and the productivity lost, respectively, due to illness. In this study, the economic costs of inadequate physical activity were estimated using the cost-of-illness methodology combined with a top-down approach and population attributable fractions (PAFs) ${ }^{43} 44$ Direct cost components were estimated using the prevalence method, while indirect costs components were calculated, following established methodology, as the expected values from future lost production using the human capital approach with cumulative expected losses over a working life time. Direct cost components include hospital-based inpatient and outpatient care and primary care. Prescription drugs were not included. The Swedish Pharmaceutical register (the Swedish National Board of Health and Welfare), comprising information about prescribed and dispenses pharmaceuticals, does not contain any diagnostic information. In the discussion, we provide a comparison of total sales, without any estimates of the amounts attributable to insufficient physical activity, of relevant pharmaceutical for the years 2002 and 2016. Indirect cost components include market and household-based productivity losses due to mortality and work disability (early retirement).

Total numbers of hospitalisations and hospital visits, in Sweden, by disease category were collected from the national register administrated by the Swedish National Board of Health and Welfare. No national registry exists for primary care. Instead, the total number of primary-care visits was estimated using data collected from the administrative registry in the region of Västra Götaland (VGR) (about 1.7 million inhabitants out of a total of 10 million; the figures for VGR were multiplied by 5.9). The estimates of the number of life years and working years lost due to mortality and permanent disability were based on data on mortality and newly granted early retirement by medical condition, age and sex (National Board of Health and Welfare, Causes of Death Register; Försäkringskassan, government agency administrating social security) and life tables for the years 2002 and 2016 (Statistics Sweden).

Unit costs for hospitalisations, per medical condition, were collected from the cost-per-patient database administrated by the Swedish Association of Local Authorities and Regions, while unit costs for hospital visits and visits to primary care were collected from the VGR county council. The number of lost working years was converted into monetary units by multiplying by average annual wages (Statistics Sweden), including the employer contribution to social insurance. Further, a monetary value was estimated for lost household production, based on survey information on household time use patterns (Statistics Sweden). We assumed that permanent disability prevented the retirees from performing any household work. Present values of future market and household production were discounted at $5 \%$.

Available information about physical activity among Swedish adults permits us to calculate PAFs separately for physical inactivity, $P A F_{i a}$, and physical irregular activity, $P A F_{\text {ira }}$, using the formulas:

$$
\begin{gathered}
P A F_{i a}=\frac{s_{i a}\left(r_{i a}-1\right)}{1+s_{i a}\left(r r_{i a}-1\right)+s_{i r a}\left(r r_{i r a}-1\right)} \\
P A F_{i r a}=\frac{s_{i r a}\left(r r_{i a}-1\right)}{1 s_{i a}\left(r r_{i a}-1\right) s_{i r a}\left(r r_{i r a}-1\right)}
\end{gathered}
$$

where $s_{i a}$ and $s_{i r a}$ are the shares inactive and irregularly active in the population, $r r_{i a}$ and $r r_{i r a}$ are the (unadjusted) relative risks of disease among inactive and irregularly active. The shares of physically inactive and irregularly active in the Swedish population are collected from the Survey of Living Conditions (Statistics Sweden). We used the relative risks for disease reported by Garrett $e t a l$, which are calculated for an adult population (aged $>18$ ), together with physical exercise habits for the Swedish population aged 16-64 in 1996/1996 and 2008/2009 in order to calculated population attributable proportions for 2002 and 2016 (there is no reporting for the age group 18-64). ${ }^{34}$ The attributable proportions calculated in this way are likely to be lower than the 'true' proportions, since the relative risks reported by Garrett et al are valid for those aged $>18$ years of age, and since the relative morbidity risk associated with insufficient physical activity is lower among those above 64 years of age (the absolute risk of illness is increasing with age). The following medical conditions were included: ischaemic heart disease, hypertension, stroke, depression and anxiety, breast cancer, colon cancer, osteoporosis and diabetes type 2. Table 1 summarises exercise habits and the corresponding PAFs for each included disease.

The Survey of Living Conditions (SLC) comprises information as to the intensity and regularity of the respondents' physical activity on a five-point scale: 1 corresponds to no physical exercise at all; 2 corresponds to physical exercise now and then; 3 corresponds to physical exercise regularly at least once a week; 4 corresponds to physical exercise regularly about twice a week and 5 corresponds to high intensive physical exercise at least twice a week. The relative mortality risks reported by Garrett et al. $(2004)^{34}$ are computed for three levels of physical exercise regularity: inactive, irregularly active and regularly active. In order to align the Survey-of-Living-Conditions information with the information provided by Garrett et al, we assumed that the five levels in the SLC correspond to the levels in Garrett $e t$ al as follows: level 1 in the SLC corresponds to inactive; levels 2 and 3 correspond to irregularly active and levels 4 and 5 correspond to regularly active.

\section{RESULTS}

The number of hospitalisation, visits to a hospital clinic, primary care visits, the number of deaths and the number of early retirements attributable to insufficient physical activity are summarised, per medical condition and separately for the years 2002 and 2016, in table 2 . The number of lost working years and lost life years 
Table 1 Physical exercise habits and population attributable proportions (2002 and 2016; men and women)

\begin{tabular}{|c|c|c|c|c|c|}
\hline \multirow[b]{3}{*}{ Disease } & \multirow[b]{3}{*}{ ICD-10 codes } & \multicolumn{4}{|c|}{ PAF $(\%)$ corresponding to insufficient physical activity } \\
\hline & & \multicolumn{2}{|l|}{2016} & \multicolumn{2}{|l|}{2002} \\
\hline & & Men & Women & Men & Women \\
\hline Colon cancer & C18 & 21.0 & 17.0 & 25.0 & 23.0 \\
\hline Breast cancer & C50 & 11.7 & 9.3 & 14.0 & 13.0 \\
\hline Hypertension & $110-115$ & 11.7 & 9.3 & 14.0 & 13.0 \\
\hline Angina & 120 & 21.0 & 17.0 & 25.0 & 23.0 \\
\hline Ischaemic heart disease & $121-125$ & 21.0 & 17.0 & 25.0 & 23.0 \\
\hline Stroke & 161,163 & 21.0 & 17,0 & 25.0 & 23,0 \\
\hline Depression and anxiety & F30-F43, F53 & 6.9 & 5.4 & 8.0 & 8.0 \\
\hline Diabetes & $\mathrm{E} 11$ & 11.7 & 9.3 & 14.0 & 13.0 \\
\hline Osteoporosis & M80-M82 & 21.0 & 17.0 & 25.0 & 23.0 \\
\hline
\end{tabular}

PAF, population attributable fraction.

attributable to insufficient physical activity are reported in table 3. We have also calculated the relations between lost life years and the number of deaths and total lost life years (for all illness). Total monetary costs associated with the healthcare utilisation and productivity losses, attributable to insufficient physical activity, are reported in table 4 (the costs calculated for 2002 were inflated to
2016 prices using the Swedish Consumer Price Index). In table 5, we report the direct and indirect costs attributable to insufficient physical activity in relation to total direct and indirect cost, for the years 2002 and 2016. Specific result and remarks follow below.

First, the number of hospitalisations due to insufficient physical activity has decreased, between 2002 and 2016,

Table 2 Healthcare utilisation, mortality and early retirements due to insufficient physical activity

\begin{tabular}{|c|c|c|c|c|c|c|c|c|c|c|}
\hline & \multicolumn{2}{|c|}{$\begin{array}{l}\text { Number of } \\
\text { hospitalisations } \\
\text { (inpatient care) }\end{array}$} & \multicolumn{2}{|c|}{$\begin{array}{l}\text { Number of hospital } \\
\text { visits (outpatient } \\
\text { care) }\end{array}$} & \multicolumn{2}{|c|}{$\begin{array}{l}\text { Number of visits in } \\
\text { primary care }\end{array}$} & \multicolumn{2}{|c|}{$\begin{array}{l}\text { Number of deaths } \\
\text { (16-64 years of age) }\end{array}$} & \multicolumn{2}{|c|}{$\begin{array}{l}\text { Number of early } \\
\text { retirements (16-64 } \\
\text { years of age) }\end{array}$} \\
\hline & 2002 & 2016 & 2002 & 2016 & 2002 & 2016 & 2002 & 2016 & 2002 & 2016 \\
\hline \multicolumn{11}{|l|}{ Men } \\
\hline Colon cancer & 749 & 653 & 1717 & 2100 & Missing & 1368 & 44 & 31 & 5 & 1 \\
\hline Breast cancer & 7 & 6 & 62 & 46 & 47 & 32 & 1 & 0 & 0 & - \\
\hline Hypertension & 334 & 177 & 2546 & 2370 & 53785 & 130292 & 4 & 8 & 39 & 1 \\
\hline Angina & 6459 & 2068 & 4541 & 2859 & 24066 & 8214 & 1 & 1 & 93 & 2 \\
\hline Ischaemic heart disease & 5077 & 4662 & 5738 & 7129 & 9548 & 46912 & 350 & 179 & 146 & 9 \\
\hline Stroke & 3964 & 3062 & 1472 & 1571 & Missing & 20737 & 61 & 26 & 99 & 28 \\
\hline Depression and anxiety & 771 & 1243 & 3367 & 11531 & 32883 & 53847 & 0 & 0 & 273 & 83 \\
\hline Diabetes & 494 & 414 & 4848 & 6054 & 22268 & 79275 & 2 & 4 & 16 & 4 \\
\hline Osteoporosis & 57 & 17 & 284 & 374 & 3283 & 3187 & - & - & 5 & - \\
\hline Total & 17913 & 12302 & 24574 & 34035 & 145880 & 343864 & 463 & 248 & 677 & 128 \\
\hline \multicolumn{11}{|l|}{ Women } \\
\hline Colon cancer & 616 & 473 & 669 & 488 & Missing & 166 & 34.4 & 23.0 & 3 & 1 \\
\hline Breast cancer & 658 & 323 & 7483 & 2348 & 1422 & 1370 & 67.4 & 35.1 & 42 & 4 \\
\hline Hypertension & 256 & 158 & 1008 & 640 & 27183 & 32431 & 1.3 & 1,3 & 36 & 1 \\
\hline Angina & 2695 & 519 & 903 & 311 & 3992 & 734 & 1.2 & 0,2 & 40 & 0 \\
\hline Ischaemic heart disease & 3218 & 1551 & 959 & 526 & 1571 & 2759 & 91.5 & 39.2 & 38 & 1 \\
\hline Stroke & 3204 & 1885 & 348 & 366 & Missing & 3626 & 31.4 & 10.7 & 42 & 11 \\
\hline Depression and anxiety & 312 & 233 & 3414 & 14799 & 42166 & 85506 & 0.2 & 0.1 & 419 & 104 \\
\hline Diabetes & 308 & 132 & 1202 & 996 & 8744 & 14770 & 0.8 & 1.4 & 9 & 1 \\
\hline Osteoporosis & 305 & 101 & 571 & 458 & 6503 & 2249 & 0.0 & 0.0 & 15 & 1 \\
\hline Total & 11570 & 5375 & 16557 & 20931 & 91581 & 143612 & 228 & 111 & 645 & 124 \\
\hline
\end{tabular}


Table 3 Lost working years and lost life years due to insufficient physical activity, and lost life years due to insufficient physical activity in relation to the number of death and in relation to lost life years for illnesses

\begin{tabular}{|c|c|c|c|c|c|c|c|c|c|c|}
\hline & \multicolumn{2}{|c|}{$\begin{array}{l}\text { Lost working years } \\
\text { (mortality) }\end{array}$} & \multicolumn{2}{|c|}{$\begin{array}{l}\text { Lost working years } \\
\text { (early retirement) }\end{array}$} & \multicolumn{2}{|c|}{ Lost life years } & \multicolumn{2}{|c|}{$\begin{array}{l}\text { Lost life years/ } \\
\text { number of deaths }\end{array}$} & \multicolumn{2}{|c|}{$\begin{array}{l}\text { Lost life years/lost } \\
\text { life years for all } \\
\text { illness }\end{array}$} \\
\hline & 2002 & 2016 & 2002 & 2016 & 2002 & 2016 & 2002 & 2016 & 2002 & 2016 \\
\hline \multicolumn{11}{|l|}{ Men } \\
\hline Colon cancer & 363 & 295 & 35 & 5 & 1728 & 1502 & 10 & 11 & $0.94 \%$ & $0.48 \%$ \\
\hline Breast cancer & 8 & 2 & 0 & - & 22 & 12 & 17 & 12 & $0.01 \%$ & $0.00 \%$ \\
\hline Hypertension & 34 & 61 & 224 & 7 & 220 & 403 & 7 & 8 & $0.12 \%$ & $0.13 \%$ \\
\hline Angina & 10 & 2 & 522 & 7 & 126 & 45 & 6 & 8 & $0.07 \%$ & $0.01 \%$ \\
\hline Ischaemic heart disease & 2531 & 1387 & 823 & 54 & 15468 & 8177 & 8 & 10 & $8.38 \%$ & $2.60 \%$ \\
\hline Stroke & 469 & 239 & 653 & 189 & 2845 & 1281 & 8 & 9 & $1.54 \%$ & $0.41 \%$ \\
\hline Depression and anxiety & 2 & 0 & 3137 & 1403 & 9 & 7 & 7 & 7 & $0.01 \%$ & $0.00 \%$ \\
\hline Diabetes & 12 & 27 & 99 & 25 & 141 & 221 & 6 & 9 & $0.08 \%$ & $0.07 \%$ \\
\hline Osteoporosis & - & - & 40 & - & 1 & 2 & 3 & 4 & $0.00 \%$ & $0.00 \%$ \\
\hline Total & 3430 & 2012 & 5533 & 1689 & 20560 & 11650 & 72 & 78 & & \\
\hline \multicolumn{11}{|l|}{ Women } \\
\hline Colon cancer & 284 & 214 & 17 & 5 & 1651 & 1112 & 10 & 11 & $0.71 \%$ & $0.30 \%$ \\
\hline Breast cancer & 705 & 379 & 318 & - & 2363 & 1405 & 15 & 15 & $1.02 \%$ & $0.38 \%$ \\
\hline Hypertension & 12 & 5 & 220 & 7 & 166 & 170 & 6 & 6 & $0.07 \%$ & $0.05 \%$ \\
\hline Angina & 6 & 0 & 244 & 7 & 94 & 21 & 6 & 6 & $0.04 \%$ & $0.01 \%$ \\
\hline Ischaemic heart disease & 664 & 283 & 239 & 54 & 6861 & 2510 & 7 & 8 & $2.95 \%$ & $0.67 \%$ \\
\hline Stroke & 256 & 81 & 363 & 189 & 2171 & 749 & 7 & 8 & $0.93 \%$ & $0.20 \%$ \\
\hline Depression and anxiety & 1 & 0 & 4547 & 1403 & 9 & 8 & 5 & 7 & $0.00 \%$ & $0.00 \%$ \\
\hline Diabetes & 4 & 7 & 76 & 25 & 90 & 93 & 7 & 8 & $0.04 \%$ & $0.02 \%$ \\
\hline \multirow[t]{2}{*}{ Osteoporosis } & - & - & 74 & - & 10 & 6 & 3 & 0 & $0.00 \%$ & $0.00 \%$ \\
\hline & 1932 & 971 & 6098 & 1689 & 13414 & 6072 & 66 & 68 & & \\
\hline
\end{tabular}

Table 4 Total costs, healthcare utilisation, mortality and early retirements due to insufficient physical activity (millions SEK)

\begin{tabular}{|c|c|c|c|c|c|c|c|c|c|c|}
\hline \multirow[b]{2}{*}{ Men and women } & \multicolumn{2}{|c|}{$\begin{array}{l}\text { Hospitalisations } \\
\text { (inpatient care) }\end{array}$} & \multicolumn{2}{|c|}{$\begin{array}{l}\text { Hospital visits } \\
\text { (outpatient care) }\end{array}$} & \multicolumn{2}{|c|}{$\begin{array}{l}\text { Visits in primary } \\
\text { care }\end{array}$} & \multicolumn{2}{|c|}{$\begin{array}{l}\text { Deaths } \\
\text { (16-64 years of age) }\end{array}$} & \multicolumn{2}{|c|}{$\begin{array}{l}\text { Early retirements } \\
\text { (16-64 years of age) }\end{array}$} \\
\hline & 2002 & 2016 & 2002 & 2016 & 2002 & 2016 & 2002 & 2016 & 2002 & 2016 \\
\hline Colon cancer & 56 & 129 & 19 & 19 & Missing & 1 & 226 & 210 & 20 & 3 \\
\hline Breast cancer & 55 & 31 & 65 & 19 & 0.04 & 0.03 & 222 & 150 & 113 & 13 \\
\hline Hypertension & 11 & 10 & 111 & 12 & 45 & 116 & 16 & 29 & 173 & 4 \\
\hline Angina & 166 & 153 & 61 & 11 & 20 & 7 & 6 & 1 & 307 & 4 \\
\hline Ischaemic heart disease & 361 & 359 & 42 & 36 & 8 & 42 & 1197 & 751 & 432 & 29 \\
\hline Stroke & 210 & 357 & 5 & 14 & Missing & 18 & 260 & 141 & 386 & 128 \\
\hline Depression and anxiety & 44 & 85 & 86 & 89 & 28 & 48 & 1 & 0 & 2619 & 1014 \\
\hline Diabetes & 13 & 28 & 51 & 35 & 19 & 71 & 6 & 16 & 67 & 15 \\
\hline Osteoporosis & 28 & 7 & 27 & 7 & 3 & 3 & - & - & 45 & 13 \\
\hline Total cost & 943 & 1159 & 467 & 242 & 122 & 306 & 1933 & 1298 & 4161 & 1223 \\
\hline \multicolumn{11}{|l|}{ Total cost per year } \\
\hline 2002 & 7627 & & & & & & & & & \\
\hline 2016 & 4228 & & & & & & & & & \\
\hline
\end{tabular}


Table 5 Healthcare costs and productivity losses due to insufficient physical activity in relation to healthcare costs and productivity losses for all illness (0-64 years of age)

\begin{tabular}{|c|c|c|c|c|c|c|}
\hline & \multicolumn{2}{|c|}{$\begin{array}{l}\text { Costs due to insufficient physical } \\
\text { activity (current prices; millions } \\
\text { SEK) }\end{array}$} & \multicolumn{2}{|c|}{$\begin{array}{l}\text { Total costs (for all illness) } \\
\text { (current prices; billions } \\
\text { SEK) }\end{array}$} & \multicolumn{2}{|c|}{$\begin{array}{l}\text { Costs due to insufficient } \\
\text { activity/costs for all } \\
\text { illness }\end{array}$} \\
\hline & 2002 & 2016 & 2002 & 2016 & 2002 & 2016 \\
\hline Healthcare (excluding pharmaceuticals) & 1198 & 2178 & 140 & 240 & $0.86 \%$ & $0.91 \%$ \\
\hline Mortality & 1667 & 1298 & 24 & 60 & $7.04 \%$ & $2.16 \%$ \\
\hline Early retirement & 3587 & 1223 & 154 & 21 & $2.32 \%$ & $5.85 \%$ \\
\hline
\end{tabular}

by more than $50 \%$ for women. For men, the decrease is a more moderate $31 \%$. During the same time period the other healthcare components underwent a corresponding increase. Men increased their number of visits to a hospital clinic by $38 \%$ and women by $26 \%$. The increase in the number of visits in primary care due to insufficient physical activity is even more pronounced: $136 \%$ for men and $57 \%$ for women. The number of patients receiving inpatient or outpatient care increased from about 29500 in 2002 to about 35400 in 2016. During the same time period, the number of deaths attributable to insufficient physical activity decreased with about $50 \%$ for both men and women. In monetary terms, these developments translate into total healthcare costs, attributable to insufficient physical activity, at about 1.5 billion SEK in 2002 and 1.7 billion SEK in 2016.

Second, among men, the number of lost life years due to insufficient physical activity declined from 20560 in 2002 to 11650 in 2016. The development between the 2 years of the share of lost life years for all illness that is attributable to insufficient physical activity declined reflected this development. For instance, men who died because of ischaemic heart disease attributable to insufficient physical activity declined from about $8.4 \%$ in 2002 to about $2.6 \%$ in 2016. Similar developments were found among women.

Third, healthcare costs due to morbidities attributable to insufficient physical activity represented $0.86 \%$ of total healthcare expenditures in 2002 and $0.91 \%$ in 2016. The corresponding figures for mortality were $7.04 \%$ and $2.16 \%$.

\section{DISCUSSION}

In this study, we have derived estimates of the societal costs attributable to insufficient physical activity in Sweden for the years 2002 and 2016. We used an epidemiological approach employing PAFs based relative risks derived by Garrett $e t a b^{34}$ and exercise habits among adult swedes in 1996/1997 and 2008/2009. ${ }^{34}$ To the best of our knowledge, this is the first study of the costs of insufficient physical activity performed for Sweden. The overall conclusion emerging from our calculations is that the adverse health effects associated with physical inactivity causes large economic costs. The costs attributable to insufficient physical activity are of the same order of magnitude as the costs attributable to smoking, which is, arguably, the life style factor that has the most serious health consequences. ${ }^{42}$ Bolin and Lindgren estimated the societal costs of smoking using the same methodology as adopted in this study and arrived at a total cost of 8.3 billion for the year 2002, compared with our estimate of the costs in 2002 for insufficient physical activity, 6.6 billion (in 2002 prices; excluding pharmaceuticals). ${ }^{43}$ Insufficient physical activity was estimated to account for $0.86 \%$ and $0.91 \%$ of total healthcare expenditures in Sweden in 2002 and 2016. The corresponding 2001 figure for smoking is $1.3 \%$. Compared with earlier studies performed with similar methodological approaches for other countries the shares estimated in this study are considerably lower. For instance, Colditz estimated that $2.4 \%$ of total US healthcare expenditures in 1995 were attributed to physical inactivity, and Katzmarzyk et al found that the corresponding figure in Canada in 1999 was $2.5 \% .{ }^{32} 33$ Our results, however, fall within the range of shares of total healthcare expenditures, for a variety of countries, accounted for by insufficient physical activity reported by Ding et al in their recent review. ${ }^{42}$ Further, although 13 of the studies included in the Ding et al review incorporated indirect costs, there are methodological differences and reporting uncertainties that make comparisons with our results difficult, if not futile. Ding et al calculated direct and indirect per-country costs for 2013. ${ }^{42}$ For Sweden, their mortality-related productivity losses amounted to about $50 \%$ of the direct costs. We estimated the value of productivity losses for deaths occurring in 2016 at about $72 \%$ of the healthcare costs, which is in the same order of magnitude as the Ding et al measure.

Information about drug prescriptions and associated diagnoses is not systematically collected in Sweden. Information about total pharmaceutical sales per ATC code is available at the Swedish ehealth Agency, since 2014. The total cost for prescribed pharmaceuticals in 2016, for appropriate ATC codes (see box 1), amounted to about 6.4 billion SEK. The corresponding figure for 2002 was 4.7 billion SEK (in 2016 prices). Ignoring the complication that several pharmaceuticals have multiple indications and employing the average population attributable proportions (arithmetic averages over the included diseases) for the 2 years, yields the following estimates of the pharmaceutical costs attributable to insufficient physical activity for the years 2002 and 2016, 940 million SEK and 880 million SEK. 
Box 1. ATC codes for the pharmaceuticals included in the calculation provided in the discussion
A12A
B01A
C01A
C01D
C03A
$\mathrm{CO3C}$
CO3D
CO3E
C07A
$\mathrm{COB}$
C09
C09A
$\mathrm{CO9B}$
$\mathrm{CO9C}$
CO9D
C10
G03C
G03D
G03F
LO2B
M05B
N02A
N05A
N05B
N05C
N06A

A number of caveats should be addressed. First, we have not made any attempts at estimating the monetary value of reduced quality of life among those struck by illness. Obviously, these intangible costs are potentially considerable. Second, we have assumed that the population attributable proportions are applicable to the Swedish populations that we studied, although using relative morbidity/mortality risks estimated for a different population. The relative risks associated with physical inactivity are conditional on given life style habits in the specific population used for obtaining estimates. Any change in health-related life style habits other than physical activity in that population will change the relative risks associated with physical inactivity. For example, consider the thought experiment in which every smoker quitted smoking at a given point in time. Over time, the incidence of ischaemic heart disease will decline, ceteris paribus. However, the cases of ischaemic heart disease that still occur will not be caused by smoking, and, hence, the relative risk for ischaemic heart disease associated with physical inactivity will increase as a consequence of the smoke stop. Third, we did not include the productivity losses due to temporary illness caused by the diseases included, which is probably the most serious limitation. The reason for this is that there is no systematic collection of sickness absenteeism from work per diagnosis in Sweden. The Swedish Social Insurance Agency do collect information about sickness absenteeism per diagnosis, but only for days reimbursed
Box 2. What are the new findings and what are the implications for clinical practice?

- Physical exercise habits improved somewhat between 2002 and 2016, causing a decrease in the proportions of the economic costs that can be attributed to insufficient physical activity.

- Healthcare utilisation, hospital and primary care visits, due to the conditions associated with insufficient physical activity increased over the period.

- Total healthcare costs attributable to insufficient physical activity increased as a share of total healthcare expenditures between 2002 and 2016.

- Improvements in physical exercise habits curb future healthcare expenses and initiatives aiming at achieving such improvements are likely to be cost effective or even cost saving.

beyond the 14th day of sickness for each case of work absenteeism.

The findings are summarised in the box 2 .

Contributors $\mathrm{KB}$ is the sole contributor.

Funding This study has been funded by the Swedish organisation for outdoor life (Svenskt Friluftuftliv).

Competing interests None declared.

Patient consent Not required.

Provenance and peer review Not commissioned; internally peer reviewed.

Open access This is an open access article distributed in accordance with the Creative Commons Attribution Non Commercial (CC BY-NC 4.0) license, which permits others to distribute, remix, adapt, build upon this work non-commercially, and license their derivative works on different terms, provided the original work is properly cited, appropriate credit is given, any changes made indicated, and the use is non-commercial. See: http://creativecommons.org/licenses/by-nc/4.0/

\section{REFERENCES}

1. Paffenbarger RS, Hyde RT, Wing AL, et al. The association of changes in physical-activity level and other lifestyle characteristics with mortality among men. N Engl J Med 1993;328:538-45.

2. Paffenbarger RS, Kampert JB, Lee IM, et al. Changes in physical activity and other lifeway patterns influencing longevity. Med Sci Sports Exerc 1994:26:857-65.

3. Blair SN, Kohl HW, Barlow CE, et al. Changes in physical fitness and all-cause mortality. A prospective study of healthy and unhealthy men. JAMA 1995;273:1093-8.

4. Lee IM, Hsieh CC, Paffenbarger RS. Exercise intensity and longevity in men. The harvard alumni health study. JAMA 1995;273:1179-84.

5. Sesso HD, Paffenbarger RS, Lee IM. Physical activity and coronary heart disease in men: the harvard alumni health study. Circulation 2000;102:975-80.

6. Wannamethee SG, Shaper AG. Physical activity in the prevention of cardiovascular disease: an epidemiological perspective. Sports Med 2001;31:101-14.

7. Gorelick PB, Sacco RL, Smith DB, et al. Prevention of a first stroke: a review of guidelines and a multidisciplinary consensus statement from the national stroke association. JAMA 1999;281:1112-20.

8. Wannamethee SG, Shaper AG. Physical activity and the prevention of stroke. J Cardiovasc Risk 1999;6:213-6.

9. Hu FB, Stampfer MJ, Colditz GA, et al. Physical activity and risk of stroke in women. JAMA 2000;283:2961-7.

10. Uusitupa M, Siitonen O, Pyörälä K, et al. The relationship of cardiovascular risk factors to the prevalence of coronary heart disease in newly diagnosed type 2 (non-insulin-dependent) diabetes. Diabetologia 1985;28:653-9.

11. Helmrich SP, Ragland DR, Leung RW, et al. Physical activity and reduced occurrence of non-insulin-dependent diabetes mellitus. $N$ Engl J Med Overseas Ed 1991;325:147-52.

12. Kaye SA, Folsom AR, Sprafka JM, et al. Increased incidence of diabetes mellitus in relation to abdominal adiposity in older women. J Clin Epidemiol 1991;44:329-34. 
13. Hu FB, Manson JE, Stampfer MJ, et al. Diet, lifestyle, and the risk of type 2 diabetes mellitus in women. N Engl J Med 2001;345:790-7.

14. Hu FB, Leitzmann MF, Stampfer MJ, et al. Physical activity and television watching in relation to risk for type 2 diabetes mellitus in men. Arch Intern Med 2001;161:1542-8.

15. Fulton-Kehoe D, Hamman RF, Baxter J, et al. A case-control study of physical activity and non-insulin dependent diabetes mellitus (NIDDM). Ann Epidemiol 2001;11:320-7.

16. Pfohl M, Schatz H. Strategies for the prevention of type 2 diabetes. Exp Clin Endocrinol Diabetes 2001;109 Supp 2:S240-S249.

17. Brownson RC, Zahm SH, Chang JC, et al. Occupational risk of colon cancer. An analysis by anatomic subsite. Am J Epidemiol 1989;130:675-87.

18. Brownson RC, Chang JC, Davis JR, et al. Physical activity on the job and cancer in Missouri. Am J Public Health 1991;81:639-42.

19. Dosemeci M, Hayes RB, Vetter R, et al. Occupational physical activity, socioeconomic status, and risks of 15 cancer sites in Turkey. Cancer Causes Control 1993;4:313-21.

20. Giovannucci E, Ascherio A, Rimm EB, et al. Physical activity, obesity, and risk for colon cancer and adenoma in men. Ann Intern Med 1995;122:327-34.

21. Sesso HD, Paffenbarger RS, Lee IM. Physical activity and breast cancer risk in the college alumni health study (United States). Cancer Causes Control 1998;9:433-9.

22. Friedenreich CM. Physical activity and cancer prevention: from observational to intervention research. Cancer Epidemiol Biomarkers Prev 2001;10:287-301.

23. Holmes MD, Chen WY, Feskanich D, et al. Physical activity and survival after breast cancer diagnosis. JAMA 2005;293:2479-86.

24. Rubin K, Schirduan V, Gendreau P, et al. Predictors of axial and peripheral bone mineral density in healthy children and adolescents, with special attention to the role of puberty. $J$ Pediatr 1993;123:863-70.

25. Nichols DL, Sanborn CF, Bonnick SL, et al. The effects of gymnastics training on bone mineral density. Medicine \& Science in Sports \& Exercise 1994;26:1220-5.

26. Kohrt WM, Snead DB, Slatopolsky E, et al. Additive effects of weight-bearing exercise and estrogen on bone mineral density in older women. J Bone Miner Res 1995;10:1303-11.

27. Ross CE, Hayes D. Exercise and psychologic well-being in the community. Am J Epidemiol 1988;127:762-71.
28. Camacho TC, Roberts RE, Lazarus NB, et al. Physical activity and depression: evidence from the Alameda County Study. Am J Epidemiol 1991;134:220-31.

29. Weyerer S. Physical inactivity and depression in the community. Evidence from the upper bavarian field study. Int J Sports Med 1992;13:492-6

30. Fox KR. The influence of physical activity on mental well-being. Public Health Nutr 1999;2:411-8.

31. Manning WG, Keeler EB, Newhouse JP. The costs of poor health habits. A rand study. Cambridge, Mass: Harvard University Press, 1991.

32. Colditz GA. Economic costs of obesity and inactivity. Med Sci Sports Exerc 1999;31(11 Suppl):S663-7.

33. Katzmarzyk PT, Gledhill N, Shephard RJ. The economic burden of physical inactivity in Canada. CMAJ 2000;163:1435-40.

34. Garrett NA, Brasure M, Schmitz KH, et al. Physical inactivity: direct cost to a health plan. Am J Prev Med 2004;27:304-9.

35. Allender S, Foster C, Scarborough P, et al. The burden of physical activity-related ill health in the UK. J Epidemiol Community Health 2007;61:344-8.

36. Janssen I. Health care costs of physical inactivity in canadian adults. Appl Physiol Nutr Metab 2012;37:803-6.

37. Zhang J, Chaaban J. The economic cost of physical inactivity in China. Prev Med 2013;56:75-8.

38. Kruk J. Health and economic costs of physical inactivity. Asian Pac J Cancer Prev 2014;15:7499-503.

39. Li L. The financial burden of physical inactivity. J Sport Health Sci 2014;3:58-9.

40. Bielemann RM, Silva BG, Coll CV, et al. Burden of physical inactivity and hospitalization costs due to chronic diseases. Rev Saude Publica 2015;49:2-8.

41. Ding D, Kolbe-Alexander T, Nguyen B, et al. The economic burden of physical inactivity: a systematic review and critical appraisal. $\mathrm{Br} J$ Sports Med 2017;51:1392-409.

42. Ding D, Lawson KD, Kolbe-Alexander TL, et al. The economic burden of physical inactivity: a global analysis of major noncommunicable diseases. Lancet 2016;388:1311-24.

43. Bolin K, Lindgren B. Rökning - produktionsbortfall och sjukvårdskostnader. Stockholm: Statens Folkhälsoinstitut, 2004.

44. Bolin K, Lindgren B. Smoking, healthcare cost, and loss of productivity in Sweden 2001. Scand J Public Health 2007;35:187-96. 